Artículo de posesión

\title{
Bioeconomía: el futuro sostenible
}

\author{
Elizabeth Hodson de Jaramillo
}

Facultad de Ciencias, Pontificia Universidad Javeriana, Bogotá, D.C., Colombia

Artículo de posesión para el ingreso como miembro de número a la

Academia Colombiana de Ciencias Exactas, Físicas y Naturales el 20 de junio de 2018

\begin{abstract}
Resumen
La actividad humana intensiva y los modelos de desarrollo convencionales basados en los combustibles fósiles han ocasionado graves impactos en el entorno. Debido a ello, el mundo enfrenta una serie de grandes desafíos ambientales, económicos y sociales que deben ser atendidos si queremos garantizar un futuro con bienestar para todos y enfrentar el cambio climático progresivo, la vulnerabilidad de algunas regiones, la reducción de la biodiversidad, la seguridad alimentaria y nutricional, el agotamiento del agua y el suelo, y las desigualdades sociales. En ese sentido, es claro que continuar con el mismo modelo de desarrollo no es una opción y, por lo tanto, es indispensable adaptar los patrones económicos y sociales si se desea cumplir con los objetivos de desarrollo sostenible de las Naciones Unidas. En el presente documento se plantea el modelo de la bioeconomía como propuesta integral de un desarrollo con sostenibilidad ambiental, social y económica. Lo que diferencia este nuevo modelo económico de otros es el hecho de la incorporación del conocimiento y de avances científicos y tecnológicos para el desarrollo de nuevas alternativas y senderos productivos que impulsen la aplicación de nuevas tecnologías en el aprovechamiento sostenible de los recursos y procesos biológicos, con el fin de proveer bienes y servicios en todos los sectores económicos con el fin de migrar de la insostenible economía basada en combustibles fósiles a la economía de la biomasa renovable. Para que sea exitosa, la adopción de este modelo requiere de voluntad política para la adopción de decisiones, así como de un sólido compromiso de los científicos y de todos los miembros de la sociedad. (C) 2018. Acad. Colomb. Cienc. Ex. Fis. Nat.
\end{abstract}

Palabras clave: Bioeconomía; Economía circular; Sostenibilidad; Biotecnología; Bioindustria.

Bioeconomy: A sustainable future

\begin{abstract}
Conventional fossil fuel-based development models and intensive human activity have caused severe impacts on the environment. As a result, the world faces a series of major environmental, economic and social challenges that must be addressed if future welfare for all is to be guaranteed. Renewed initiatives are necessary to face the progressive climate change and the vulnerability of some regions, biodiversity reduction, food and nutritional security, depletion of water and soil resources, as well as social inequities. It is clear that continuing with the same development model is not an option, and that it is essential to adjust the economic and social patterns in order to comply with the United Nations Sustainable Development Objectives (SDOs). This document presents the bioeconomy model as a comprehensive development proposal with environmental, social and economic sustainability. What makes this new economic model different is the incorporation of knowledge for the definition of new alternatives and productive paths, fostering the production and the intensive use of knowledge related to biological resources, processes and principles, and the sustainable supply of goods and services in all economic sectors thus migrating from the unsustainable oil-based economy to the biomass economy. In order to be successful, the adoption of this model requires decisive political determination as well as strong commitment from the scientists and all members of society. (C) 2018. Acad. Colomb. Cienc. Ex. Fis. Nat.
\end{abstract}

Key words: Bioeconomy; Circular economy; Sustainability; Biotechnology; Bioindustry.

\section{Introducción}

El mundo enfrenta una serie de grandes desafíos ambientales, económicos y sociales que deben ser atendidos si se quiere asegurar un futuro con bienestar. Con la adopción de los objetivos de desarrollo sostenible (ODS) y la puesta en marcha de la Agenda 2030 en respuesta al cambio climático progresivo y la vulnerabilidad de algunas regiones, los recursos naturales finitos, la seguridad alimentaria y nutricional, así como las desigualdades sociales, la comunidad mundial (representada en los 197 estados que

Correspondencia:

Elizabeth Hodson de Jaramillo, ehodson8@outlook.com

Recibido: 27 de abril de 2018

Aceptado: 7 de junio de 2018

Editor: Sandra Baena Garzón 
respaldaron dichos objetivos), ha reconocido el imperativo ético y social de promover un futuro con sostenibilidad social, ambiental y económica. El trasfondo general de dicha respuesta es la necesidad de evolucionar hacia un nuevo sistema económico basado en la integración del conocimiento para el uso sostenible de los recursos biológicos mediante el aprovechamiento de todos los productos y subproductos de los procesos relacionados con recursos biológicos, reduciendo tanto la generación de residuos, de desechos y de contaminación, así como la emisión de gases de efecto invernadero, todo ello en busca de una 'descarbonización' de la economía. Con el fin de diseñar procesos más eficientes basados en el precepto de "más con menos", se debe trabajar en el desarrollo de sistemas de uso integral y completo de la biomasa, como es el caso de las biorrefinerías, y definir cadenas de biomasa que incluyan el uso de residuos y subproductos de los sectores rural e industrial. Bajo estos postulados, desde finales del siglo $\mathrm{XX}$ fue surgiendo y tomando cada vez más fuerza en el mundo el concepto de la bioeconomía, también conocida como economía de base biológica, o economía bio-basada, que es la transformación del conocimiento de las ciencias de la vida en productos nuevos, sostenibles, ecoeficientes y competitivos, por lo que constituye una alternativa importante para la sostenibilidad del planeta. Se trata de un proceso disruptivo de transformación social altamente dinámico y complejo, con perspectivas de políticas a largo plazo y de cambios sociales.

\section{La sostenibilidad como responsabilidad social}

La actividad humana ha venido deteriorando las condiciones del entorno y ocasionando efectos negativos en diversos ámbitos: en el ambiente, la biodiversidad, y los recursos de agua y suelo. Por esta razón, la búsqueda de alternativas para enfrentar esta situación constituye una responsabilidad ética y social. Con el fin de cumplir con los objetivos de desarrollo sostenible y contribuir al mejoramiento del planeta, es necesario promover una transición hacia una economía más sostenible, para lo cual se requieren desarrollos innovadores en los sectores primarios que generen más tecnologías y métodos eficientes para incrementar la productividad agrícola, forestal y acuícola sin amenazar la capacidad de carga del planeta ni su biodiversidad (Lewandowski, 2018). Los nueve billones de habitantes que se estima vivirán en el planeta en el 2050, requerirán alimentos, agua limpia y energías renovables aunque decrezca progresivamente el área de suelo fértil para la agricultura debido al pastoreo intensivo, la salinización, la desertificación y el crecimiento urbano, entre otros factores, y deban atenderse las limitaciones que el cambio climático ya ha impuesto en algunas regiones (Jiménez-Sánchez \& Philp, 2015). Todo ello representa grandes desafíos interconectados de forma compleja y exige nuevos enfoques y paradigmas sociales, económicos y ambientales (Aguilar, et al., 2018).

El desarrollo de este nuevo paradigma de la bioeconomía permite responder a las demandas de la sociedad en cuanto a alimentos, ambiente, mitigación y adaptación al cambio climático, promoción de la resiliencia y gestión sostenible de recursos vitales del planeta como la biodiversidad, los suelos fértiles, el agua limpia y suficiente (Global Bioeconomy Summit-GBS, 2015a). Para lograr un máximo beneficio, deben articularse todos los sectores de la bioeconomía, pues todos son interdependientes, para, de esta manera, alcanzar la seguridad alimentaria, una mejor nutrición y salud pública, y procesos industriales más limpios y eficientes que contribuyan significativamente a la mitigación del cambio climático (Lokko, et al., 2018). Los beneficios potenciales de la transición hacia una bioeconomía incluyen la reducción de las emisiones de gases de efecto invernadero, la reducción de la dependencia de los combustibles fósiles, una gestión de recursos más sensata y la mejoría de la seguridad alimentaria. Un efecto adicional sería la generación de empleos en zonas rurales y urbanas, y la creación de mercados agrícolas diferentes a los de los alimentos y que se basen en la bioenergía y la valorización de productos, subproductos y residuos agrícolas y agroindustriales, lo que representaría una fuente de actividades y de ingresos alternativos propicios para las áreas rurales. El desafío consiste en incrementar la escala de actividades $\mathrm{y}$, paralelamente, responder a los objetivos de desarrollo sostenible introduciendo cambios radicales para enfrentar retos sociales tales como el cambio climático, la escasez de recursos naturales y la contaminación ambiental (McCormik \& Kautto, 2013).

Simultáneamente con la situación variable del petróleo en el mercado mundial, la desaceleración del rendimiento agrícola y los efectos del cambio climático, deben mejorarse los niveles vida en varias partes del mundo, principalmente en Asia, Suramérica y África sin que necesariamente vaya ligado a un incremento del consumo de carnes, especialmente, pues ello implica un mayor requerimiento de pienso, forraje y agua, y contribuye a la deforestación y a la emisión de gases de efecto invernadero (Jiménez-Sánchez \& Philp, 2015). Como ejemplo de la situación variable en algunos patrones de consumo, se presenta un incremento en la demanda de proteína animal en varios países que han incrementado su poder adquisitivo y duplicado su riqueza, en los cuales, se encuentra que las emisiones de gases han incrementado hasta en un $80 \%$ (Philp, 2018).

Estas situaciones han permitido que aumente la conciencia sobre la fragilidad de la biosfera y sobre la urgente necesidad de adoptar modelos de consumo y producción sostenibles, basados en un modelo en cascada, o circular, de la bioeconomía. Se trata de una economía que usa la biomasa en lugar de los recursos fósiles para producir alimentos y otros bienes no alimentarios, bioproductos para uso industrial, así como farmacéuticos y agrícolas, entre otros. El enfoque de la bioeconomía aspira a copiar los fundamentos de la inteligencia biológica, en la cual un ser vivo constituye una maquinaria capaz de procesar una serie de compuestos (principalmente de origen orgánico) para transformarlos en energía, biomasa y otros subproductos. 
Lo que hace a esta máquina tan especial, es que tanto las materias primas como los productos finales se integran en los ciclos naturales de sus componentes (fundamentalmente el carbono), de manera que no se generan residuos netos, ya que estos son reutilizados como materia prima por otros sistemas biológicos, cerrando así el ciclo. Precisamente por sus características y su potencial de influir en el desarrollo de productos y procesos circulares para el bienestar de la población, la biotecnología se puede considerar como uno de los soportes fundamentales de la bioeconomía.

El aprovechamiento sostenible de recursos biológicos renovables se centra en los tres pilares de la bioeconomía: la producción de alimentos y piensos, la obtención de bioproductos (preferencialmente con valor agregado) y la producción de bioenergía, e incluye varias industrias y sectores: agrícolas, forestales, pesqueros, de alimentos humanos y animales, de producción de pulpa y papel, así como parte de las industrias química, biotecnológica y de energía. Su estrategia resalta la oportunidad de lograr el crecimiento económico y al mismo tiempo garantizar la seguridad de los recursos biológicos y su uso eficaz y sostenible (Cristobal, et al., 2016). A partir de los recursos renovables se pueden enfrentar algunos de los retos de la sostenibilidad, incluido el manejo del agua y del suelo, el uso eficiente de nutrientes y el desarrollo socioeconómico. Esto se refiere a la seguridad alimentaria y nutricional (SAN) a través de la producción sostenible de alimentos, a la reducción de producción de residuos mediante un uso adecuado de los productos y procesos considerando la reducción, la reutilización y el reciclaje de los componentes de las cadenas de valor, así como a la promoción en la eficiencia del uso de recursos en la producción de biomasa, $\mathrm{y}$ al aprovechamiento por parte de la sociedad de todos los componentes de estas cadenas o redes de valor. Esta sostenibilidad debe mantenerse a través de toda la cadena de suministro, con el fin de ofrecer seguridad alimentaria, un suministro suficiente de materia prima y energía, la reducción de la huella ambiental, así como la promoción de una economía rural saludable y viable. Es indispensable reducir la generación de residuos y promover el reciclaje eficiente de los que se generen, contando con ciclos cerrados de producción y reutilización de subproductos (Lokko, et al., 2018).

\section{Conceptos generales y fundamentos de la bioeconomía}

La bioeconomía se basa en la transición de la dependencia de combustibles fósiles a una situación donde la agricultura no solo contribuya a la seguridad alimentaria sino también a la producción de biomasa como materia prima renovable para la industria, la generación de energía y otros usos. No hay una sola forma de bioeconomía sino muchas que se ajustan a las condiciones y las posibilidades de cada situación. La bioeconomía se define de maneras muy distintas alrededor del mundo y la terminología empleada también difiere, pero, en el fondo, las políticas en bioeconomía abarcan o engloban la innovación y la sostenibilidad, así como el crecimiento de la economía y el empleo. Un concepto compartido a nivel global es el de la aplicación de la investigación, el desarrollo y la innovación tecnológica para la producción y el aprovechamiento de los recursos, y los procesos y principios biológicos innovadores, con el fin de suministrar bienes y servicios de forma sostenible a todos los sectores de la sociedad, el comercio y la industria (Global Bioeconomy Summit - GBS, 2015a). Los elementos centrales de la bioeconomía son los recursos, los procesos y los principios biológicos, así como todas las tecnologías (convencionales y modernas) asociadas con su conocimiento, desarrollo, transformación o regeneración (Rodríguez, et al., 2017). Los aspectos comunes a las diversas definiciones de la bioeconomía son su relación con el conocimiento y la ciencia, la tecnología y la innovación, con la aplicación de biotecnologías y la reducción de la dependencia con respecto a los combustibles fósiles, así como el valor agregado de los productos, y los conceptos de sostenibilidad y ecoeficiencia.

La siguiente es la definición global recientemente ajustada en la Cumbre Mundial de Bioeconomía 2018 (Global Bioeconomy Summit - GBS, 2018): "la bioeconomía es la producción, utilización y conservación de recursos biológicos, incluido el conocimiento relacionado, la ciencia, la tecnología y la innovación, para suministrar información, productos, procesos y servicios en todos los sectores económicos, en busca de una economía sostenible". Se trata de un proceso de transformación social dinámico y complejo que requiere de políticas a largo plazo. La visión de una bioeconomía sostenible es la 'biologización' de la economía con nuevos procesos y productos industriales de base biológica ('biobasados'), lo que conlleva cambios en el comportamiento de los consumidores. En el fondo, es una estrategia de crecimiento sostenible que establece la armonía ecológica y económica (El-Chichakli, 2016). Abarca los sectores de la agricultura, la ganadería, los forestales, la pesquería y la acuicultura, así como las industrias relacionadas con su procesamiento: alimenticia, del papel, textil, de la construcción, química y biofarmaceútica, entre otras. Las tecnologías convergentes y habilitantes como las biológicas, la nanotecnología y las de la información, son cruciales para los procesos de base biológica, así como los principios de la ingeniería y la aplicación industrial (Consejo Alemán de Bioeconomia, 2018). El viraje hacia una economía basada en la biomasa en sustitución de los combustibles fósiles representa un cambio significativo en los sistemas socioeconómicos, agrícolas, energéticos y tecnológicos convencionales (McCormik \& Kautto, 2013). La bioeconomía apalanca innovaciones en las ciencias de la vida y en las bioindustrias para alcanzar un crecimiento ecológico y social sostenible, así como la generación de empleo con base en esta utilización sostenible de los recursos biológicos (Global Bioeconomy Summit - GBS, 2015b). Por naturaleza, la bioeconomía utiliza la biomasa renovable para obtener una variedad de productos, incluidos los alimentos para humanos y animales, nuevos bioproductos industriales, 
bioenergía y servicios ecológicos. Está por descubrirse todo un arsenal de nuevos productos y de funciones: fármacos, enzimas de interés medicinal e industrial, elementos para la resistencia y la tolerancia de condiciones adversas, la reducción de la toxicidad y las alergias, entre otros muchos (Aguilar, et al., 2018).

Este nuevo campo ha recibido múltiples nombres, bioeconomía, economía circular, crecimiento verde o economía verde, entre otros, utilizados por diversos sectores con objetivos, ámbitos y características propias, aunque todos ellos parten del mismo enfoque y comparten los objetivos de sostenibilidad social, ambiental y económica. La economía circular se refiere a una economía eficaz y eficiente en el uso de los recursos/ biomasa con baja emisión de carbono para un crecimiento inteligente, sostenible e integrador, en donde los subproductos de un proceso dado son utilizados como materia prima de otro proceso subsiguiente, es decir no se producen residuos y se mantiene el valor de los diversos componentes del sistema durante el mayor tiempo posible. La bioeconomía y la economía circular evidentemente convergen en sus objetivos y deben fortalecer sus complementariedades y sinergias para integrarse en las agendas de desarrollo sostenible y para enfrentar el cambio climático (Aguilar, et al., 2018). La búsqueda de una visión integral global sobre el uso de los recursos biológicos lleva necesariamente a una mayor inclusión de aspectos económicos en la economía circular y a una mayor visibilidad de la sostenibilidad en la bioeconomía. Así como el aspecto circular es inherente a la biología, la bioeconomía circular es una parte integral de la economía circular y la bioeconomía.

\section{Orígenes y desarrollo de la bioeconomía basada en el conocimiento}

Europa ha sido tradicionalmente líder y pionera en diversos campos de las biociencias y las tecnologías relacionadas. Las bases de la bioeconomía se originaron a partir de las agendas estratégicas tempranas de la Comisión Europea, hacia 1993, las cuales destacaban la necesidad de invertir en conocimiento y resaltaban el papel de la ciencia en la innovación y el crecimiento económico. Se puede considerar que la bioeconomía es uno de los sectores económicos más antiguos de la humanidad, aunque las ciencias de la vida y la biotecnología lo están transformando en uno de los más innovadores (McCormik \& Kautto, 2013). Con el desarrollo de los programas de biotecnología y ciencias biológicas, que sirvieron de marco para establecer una sólida cooperación trasnacional en la Unión Europea, se obtuvo un incremento de la participación de la industria que permitió fortalecer tanto la excelencia científica como el aprovechamiento industrial de los resultados (Patermann \& Aguilar, 2018). Por su parte, la Organización para la Cooperación y el Desarrollo Económicos (OECD) publicó el documento "Biotecnología para el crecimiento y desarrollo sostenibles", en el que, por primera vez a nivel global, se planteó el concepto de una bioeconomía como "un concepto que utiliza recursos biológicos renovables, bioprocesos eficientes y alianzas ecoindustriales para obtener bioproductos, empleos e ingresos sostenibles". En dicho documento se introdujeron conceptos como que los beneficios ambientales eran un elemento motivador para la bioeconomía pero no suficiente para su aceptación social. También se planteó que las biotecnologías no siempre suministran la mejor solución técnica, pero que cuando lo hacen, los beneficios ambientales y económicos son evidentes. El documento también aborda temas como la revitalización de las economías rurales, la necesidad de una mayor integración y de nuevos conocimientos, así como de una clara articulación de políticas y de la convergencia de varios sectores, planteamientos que actualmente son las bases de muchas de las estrategias en bioeconomía en el mundo (Organización para la Cooperación y el Desarrollo Económicos - OECD, 2004).

El Quinto Programa Marco de la Unión Europea (1998-2002) fue el punto de inflexión para definir las que denominó "acciones clave" enfocadas en requerimientos socioeconómicos y en objetivos de políticas de la Unión Europea. La "fábrica celular" (Cell Factory) fue una de las acciones seleccionadas con el objetivo de aprovechar la capacidad de la célula como fábrica y obtener nuevos medicamentos, productos alimenticios con propiedades nutritivas mejoradas, técnicas de degradación de compuestos recalcitrantes y enzimas industriales capaces de reemplazar procesos químicos menos amigables ambientalmente, entre otros bioproductos con alto valor agregado (Patermann \& Aguilar, 2018). Los desafíos incluían promover el avance de tecnologías innovadoras a través de la investigación orientada según la misión, la utilización industrial de los resultados y el establecimiento de alianzas entre los sectores productivos y los de investigación. Los productos esperados eran de interés socioeconómico y se relacionaban con el diagnóstico y los tratamientos en salud, con la sostenibilidad ambiental y con el mejoramiento en la calidad de los alimentos, la agroindustria y la química fina. Las destrezas desarrolladas con estos esfuerzos iniciales, y el fortalecimiento de capacidades en ciencia, tecnología e innovación fueron el cimiento para iniciar hacia el 2005 la "Bioeconomía basada en el conocimiento" (Knowledgebased Bio-Economy, KBBE), acorde con la búsqueda de economías dinámicas y competitivas mediante industrias de alta tecnología que requieren de inversiones en innovación y mano de obra altamente calificada (Lewandowsky, 2018). Las experiencias y las expectativas de la sociedad por los resultados obtenidos en esta etapa, aunadas al interés en responder a los desafíos de seguridad alimentaria, energía, agua, producción sostenible y cambio climático y simultáneamente reducir la huella ambiental de la actividad humana, llevaron a la formulación de la estrategia en bioeconomía de la Unión Europea en el 2012, expresada en el documento "Innovación para el crecimiento sostenible: una bioeconomía para Europa" (Patermann \& Aguilar, 2018). Dicha estrategia enfatiza la necesidad de una aproximación integral basada en el uso de nuevas tecnologías y en el 
fortalecimiento de la cooperación entre la ciencia y la industria, así como con los responsables de las políticas y las decisiones en los gobiernos (Małyska \& Jacobi, 2018).

Además de las iniciativas de la Unión Europea, surgieron simultáneamente otras en varios países, y diversas organizaciones internacionales formularon sus planteamientos sobre la bioeconomía. Una serie de factores convergieron para impulsar este enfoque: i) la acumulación de nuevo conocimiento sobre los recursos biológicos, plantas, animales y microorganismos, y sus procesos (secuenciamiento del ADN, desarrollo de las llamadas "ómicas"); ii) la oportunidad de combinar las ciencias biológicas con nuevos conocimientos en áreas convergentes como la informática, la nanotecnología y la biología sintética, entre otras; iii) el reconocimiento mundial de que los recursos biológicos ofrecen ventajas únicas frente a los recursos fósiles, pues son renovables, neutrales en cuanto a las emisiones de carbono, tienen circularidad (pueden reutilizarse y usarse en múltiples formas) y menor toxicidad, así como múltiples funciones, y iv) la afinidad de la bioeconomía con la sostenibilidad, pues, aunque por ser de base biológica un proceso no se convierte automáticamente en sostenible, sí es más factible que tenga un uso sostenible. Es claro que la sostenibilidad se determina por el ciclo de vida del proceso y el producto, no por colocarle una etiqueta (Patermann \& Aguilar, 2018). Hay otros factores y condiciones que estimularon la adopción del enfoque de la bioeconomía a nivel global, pero la participación de actores clave se requiere para impulsar la innovación y la transferencia de tecnología definiendo agendas de innovación y hojas de ruta claras con apoyo financiero privado y público para facilitar el intercambio de opiniones y la adopción conjunta de prioridades, requerimientos y proyecciones. Por ejemplo, el grupo de trabajo conjunto de Estados Unidos y la Unión Europea en biotecnología, el cual se concreta en la US-EU Task Force on Biotechnology Research, ha venido desarrollando una serie de actividades desde 1990 y promoviendo el estudio científico en el campo de los biomateriales y la biorrefinería.

En septiembre del 2005 se realizó en Bruselas la Conferencia en Bio-Economía Basada en el Conocimiento (Knowledge Based Bio-Economy) en cuyas deliberaciones políticas y estratégicas participaron varios países (Canadá, Estados Unidos de América, Brasil, Argentina, Sur África, India, Rusia, Australia y Nueva Zelanda), y en las mismas fechas, se llevó a cabo una conferencia en bioeconomía en China. En estos países el concepto de bioeconomía continúa vigente y se expresa en estrategias nacionales explícitas. En los años siguientes el concepto se fue consolidando con apoyo del $7^{\circ}$ Programa Marco de la Unión Europea hasta llegar a la formulación de la estrategia política en bioeconomía en febrero de 2012 (Patermann \& Aguilar, 2018).

\section{Los métodos y el componente de ciencia, tecnología e innovación}

Los sectores industriales que derivan su materia prima o sus componentes fundamentales de los recursos naturales constituyen la economía de base biológica o bioeconomía. Para contribuir al avance de los países en desarrollo y brindar estímulos a la industria de base biológica, es conveniente el uso de las biotecnologías en los diversos pasos de la cadena de valor, de manera que se asegure la sostenibilidad del sector y se reduzcan los impactos ambientales negativos que podrían presentarse. Los ejemplos en la agroindustria incluyen los 'bioinsumos', las nuevas tecnologías de procesamiento, el manejo de productos perecederos, los empaques biodegradables y las mejoras en la competitividad y la productividad. El papel de las biotecnologías va mucho más allá del crecimiento industrial, ya que abre oportunidades para avanzar en los objetivos de desarrollo sostenible (Lokko, et al., 2018). El conocimiento científico y los desarrollos tecnológicos deben transformarse en productos o servicios beneficiosos para el sector productivo, la agricultura, la bioenergía y el desarrollo de nuevos bioproductos, para lo cual debe estimularse la capacidad de emprendimiento y favorecer la articulación entre la academia, la empresa privada y el sector financiero (Aguilar, et al., 2018). Los avances en ciencia y tecnología, específicamente en biotecnología, son de relevancia sustancial para el desarrollo de la bioeconomía. Hay una enorme cantidad de información valiosa para la agricultura, el ambiente y la medicina que debe analizarse; en ese sentido, los expertos en bioinformática tienen un gran reto frente a las colecciones de megadatos y los bancos de datos en cuanto a su clasificación provechosa para investigadores $\mathrm{y}$ otros usuarios.

Los avances de la bioeconomía se han facilitado por el incremento del conocimiento y la experiencia técnica en torno a los procesos biológicos y sus aplicaciones prácticas. El desarrollo de la bioeconomía requiere de excelencia científica y de capacidades de transformación que permitan ampliar las fronteras para la utilización sostenible de toda la gama de recursos biológicos disponibles (Rodríguez, $\boldsymbol{e t}$ al., 2017). Asimismo, se necesita el respaldo de una sólida base de conocimiento, de capacidades tecnológicas y de un enfoque de innovación que permita obtener más con menos mediante el incremento de la productividad y la eficiencia de los recursos. Es necesario mejorar la eficiencia y reducir el uso de insumos como el agua, los fertilizantes, la energía en transporte, así como la generación de residuos (Aguilar, et al., 2018). La clave para la inserción de la bioeconomía en los procesos de desarrollo es que los avances científicos y tecnológicos se implementen en los procesos productivos fortaleciendo las cadenas y las redes de valor. Una cadena de valor en bioeconomía incluye desde la producción primaria de los recursos biológicos (biomasa), su procesamiento y su transformación en bienes de mayor valor y su introducción en el mercado, lo cual involucra diversos sectores y aglutina numerosas disciplinas y actores. Por esto, la bioeconomía es un campo muy amplio de investigación, desarrollo e innovación que debe apoyarse en la colaboración entre las diversas disciplinas, incluidas las ciencias agrícolas y las 
naturales, la economía y las ciencias sociales, entre otras, con un enfoque sistémico que permita facilitar la transición a una economía innovadora.

Las economías de muchos países en desarrollo se basan en la agricultura y otros recursos naturales renovables. La innovación es crítica para incrementar la productividad en la agricultura sostenible y en el sector agroalimentario, así como para la creación de empleos en sistemas productivos agrícolas, de procesamiento y en investigación y desarrollo (Sarkar, et al., 2018). Los avances biotecnológicos ofrecen innumerables alternativas para el mejoramiento de plantas, animales y microorganismos, y el desarrollo de soluciones que permitan atender los requerimientos de seguridad alimentaria y nutricional, de intensificación sostenible de la producción agrícola, así como para enfrentar los retos que presenta la adaptación de cultivos al cambio climático, con beneficios significativos tanto para el consumidor como para el ambiente; puede, asimismo, transformar las estrategias necesarias para conservar la biodiversidad (Hodson, et al., 2017). En general, la biotecnología ofrece oportunidades únicas para el desarrollo sostenible y, de hecho, ha innovado las prácticas industriales y agrícolas mejorando la diversidad y la calidad de productos que tienen mejor aceptación en el mercado internacional por provenir de este contexto de sostenibilidad. La transición a una economía baja en carbono y preferiblemente circular, y la mayor conciencia del público en torno a la sostenibilidad, han llevado a incrementar la demanda por productos y procesos con base biológica. En el sector agrícola las aplicaciones biotecnológicas han permitido incrementar la productividad, diversificar y dar valor agregado a los productos $\mathrm{y}$, paralelamente, reducir el impacto ambiental (Lokko, et al., 2018).

El desarrollo de metodologías para detectar y controlar amenazas bióticas y abióticas en la producción agrícola y para incrementar la resiliencia de los sistemas y gestionar de forma sostenible los recursos de agua y suelo es una prioridad para los investigadores (Sarkar, et al., 2018). Puesto que la agricultura utiliza alrededor de un $70 \%$ del agua dulce del planeta, cualquier medida para reducir y hacer su uso más eficiente resulta de gran impacto social y económico. La comprensión de la tolerancia al estrés, principalmente las sequías y las inundaciones en los cultivos, es una prioridad actual en la investigación agrícola y para ello se están desarrollando plantas transgénicas, o estudios de biología sintética y de edición de genes (Hodson, et al., 2017). Un problema apremiante es la sobreexplotación de algunos ecosistemas, lo que, sumado a los cambios climáticos, puede llevar a la reducción de la productividad en algunas regiones; debe recordarse, además, que en respuesta a los Objetivos de Desarrollo Sostenible, no es conveniente ampliar la frontera agrícola, sino más bien incrementar la productividad de los sistemas existentes con mayor eficiencia. La FAO plantea que mínimo un $90 \%$ del incremento en la producción agrícola debe provenir de mayores rendimientos basados en el mejoramiento de los cultivos y de mejores y más eficientes prácticas de producción, lo cual solamente puede lograrse con el mejoramiento de variedades. La investigación y el desarrollo han permitido desarrollar variedades de cultivos muy especializados, con nuevos rasgos que les permitan responder a las limitaciones, o agregar valor a los bioproductos y procesos subsecuentes haciendo más eficiente el uso del agua y de insumos (Małyska \& Jacobi, 2018). Aumentar la producción en una unidad de tierra cultivable presenta enormes beneficios ambientales y económicos porque el mayor rendimiento por superficie reduce la demanda global de suelo agrícola.

Los métodos cuantitativos y cualitativos con enfoques de alto rendimiento, como la proteómica, los análisis de expresión y secuenciación, y la tecnología de la información (megadatos), constituyen avances que facilitan y aceleran los ciclos de mejoramiento. Además de la eficiencia en el uso de insumos, la protección frente a las plagas y enfermedades, incluidas las emergentes debidas al cambio climático, y las mejoras en la composición nutricional, entre las múltiples aplicaciones de las agrobiotecnologías se encuentran los sistemas de biodegradación de residuos de la industria agroalimentaria, la biorremediación y la obtención de bioinsumos, incluidos biofertilizantes (micorrizas y fijadores de nitrógeno), así como bioplaguicidas para el control biológico, y bacterias promotoras del crecimiento vegetal (Hodson, et al., 2017). Los estudios moleculares y genómicos también son esenciales para entender y replicar los comportamientos y procesos desarrollados por los organismos a lo largo de miles de millones de años de evolución, por ejemplo, para adaptarse a diferentes condiciones ambientales (Rodríguez, et al., 2017). Una de las tecnologías más promisorias en este contexto es la que permite la edición de genomas (genome-edited crops, GEP), por sus amplias posibilidades de atender diversas limitantes de producción; es el caso del sistema de edición de genes mediante la tecnología CRISPR (clustered regularly interspaced short palindromic repeats) aplicada a la proteína Cas9 para la obtención de resistencia o tolerancia a plagas y enfermedades en aras de mejorar la calidad nutricional de los productos o buscar mecanismos de tolerancia a factores abióticos (sequías, inundaciones, salinidad) relacionados con el cambio climático. Esta tecnología presenta varias ventajas comparada con otros sistemas de mejoramiento molecular por su relativa simplicidad, así como por ser altamente específica y confiable para la edición de genes en células vegetales, animales y microbianas (Hodson, et al., 2017).

Es fundamental contar con material para los programas de mejoramiento, ya sea de los cultivos o de especies silvestres. El uso de herramientas moleculares avanzadas como la tecnología de secuenciación masiva NGS (next generation sequencing), ha permitido hacer más rápido y eficiente el proceso de evaluación y cribado de secuencias de genomas completos y de secuenciación del ARN. Esta técnica permite estudiar más detalladamente la genómica y la posgenómica (trascriptómica, proteómica, metabolómica) de los cultivos, 
así como los patrones de expresión de genes completos, y hace posible detectar líneas con rasgos de interés para enfrentar condiciones extremas. (Sarkar, et al., 2018). Como complemento de todo lo anterior, la agricultura de precisión es un apoyo valioso para aumentar la eficiencia en el uso de insumos, minimizando las entradas y maximizando la producción.

Otro de los enfoques principales de los desarrollos en bioeconomía son las biorrefinerías para la obtención de bioenergía que permita la sustitución gradual de los combustibles fósiles por bioproductos renovables, o la obtención de bioproductos. Los productos y procesos biotecnológicos son, en principio y por definición, más limpios que los procesos petroquímicos o termoquímicos. En este campo, ha habido una serie de avances en los sistemas de transformación de biomasa. Los biocombustibles iniciales, denominados de primera generación, se obtenían a partir de cultivos alimenticios como el trigo, la remolacha azucarera y las plantas oleaginosas; los llamados de segunda generación se basan en el uso de biomasa no alimenticia, como el material lignocelulósico, incluidos los residuos de las cosechas de cereales y otros cultivos, y los de tercera generación se derivan de cultivos de algas. Los principales productores de biocombustibles líquidos son los Estados Unidos, Brasil y la Unión Europea (McCormik \& Kautto, 2013). La genómica (incluida la metagenómica), por su parte, también tiene un gran potencial para la biotecnología industrial y la producción de base biológica de combustibles, químicos y plásticos. La mayor presión para la sustitución de productos derivados del petróleo no se deriva de la escasez, porque actualmente no hay carencia, sino de las presiones políticas y sociales relacionadas con la sostenibilidad, el cambio climático y la seguridad energética. La genómica y la biología sintética han tenido avances importantes generando "fábricas microbianas" que producen diversos compuestos y bioproductos, incluidos monómeros plásticos, biocombustibles y precursores de compuestos de importancia industrial (Jiménez-Sánchez \& Philp, 2015). En cuanto a la biología sintética, se han intensificado los trabajos que buscan la obtención de combustibles y otros compuestos de tipo aromático a partir de lignocelulosa, principalmente la proveniente de cultivos no alimentarios y de residuos agrícolas y forestales.

A partir de la biomasa y utilizando los avances biotecnológicos, se están produciendo compuestos básicos, como el ácido acrílico o el succínico, o materiales innovadores, como los biopolímeros o las fibras ecológicamente amigables, que permiten responder a la creciente demanda social de productos naturales, saludables y sostenibles. Esto representa una gran oportunidad para que los países en desarrollo puedan procesar y valorizar su gran riqueza y abundancia de biomasa, y transformarse de proveedores de materia prima en proveedores de productos procesados (Global Bioeconomy Summit - GBS, 2015b). Se trata de procesos de innovación basados en la adición de conocimiento y tecnologías en múltiples sectores. Por ejemplo, las enzimas, un componente primordial de la bioeconomía, especialmente en países industrializados, han permitido el desarrollo de microorganismos más eficientes y productivos mediante el uso de las llamadas tecnologías del ADN recombinante y la ingeniería de proteínas. Las más comúnmente empleadas se utilizan como agentes blanqueadores, desengrasantes y como detergentes. Su uso también ha permitido aumentar la eficiencia de los procesos de digestibilidad del alimento animal reduciendo la generación de residuos y, por lo tanto, la contaminación (Lokko, et al., 2018). Ha habido un notable desarrollo de la industria de procesamiento de alimentos y gran número de empresas se dedican a su producción (isomerasas, pectinasas, transaminasas, amilasas, galactosidasas, y proteasas como la quimosina), o a la obtención de productos de gran valor agregado, como la bromelina (proteasa utilizada en las industrias cárnica, vinícola, cervecera, cosmética y farmacéutica).

En cuanto a los recursos marinos, la denominada bioeconomía azul, son una importante fuente de recursos de biomasa para las industrias de la alimentación y la energía, con una amplia serie de cadenas de valor, por lo que son fuente de empleo y oportunidades de desarrollo industrial, así como de bienestar de la población, dado que la pesquería y la acuicultura contribuyen a la seguridad alimentaria y nutricional. La contribución de la bioeconomía azul con productos biotecnológicos como las enzimas, los biofármacos, los productos de aseo y cosmética e, incluso, las bioenergías a partir de residuos marinos o de algas, será mayor en la medida en que avancen las tecnologías actualmente en estudio (Bell, et al., 2018). Una de las graves crisis que amenaza especialmente la vida y la sanidad de los océanos es la contaminación con plásticos y desechos de envases y empaques no degradables. Los desarrollos tecnológicos han permitido que actualmente se cuente con la posibilidad de usar bioplásticos biodegradables en la mayoría de las industrias que usan material plástico convencional. Los bioplásticos, con propiedades similares a los convencionales, reducen la dependencia de combustibles fósiles y la huella de carbono (European Bioplastics, 2018).

El ideal de la bioeconomía es que no haya residuos. En este sentido, y, asociado al concepto de biorrefinería, también debe mencionarse la posibilidad de cerrar ciclos mediante la utilización productiva de la biomasa de desecho derivada de procesos de producción y consumo (Rodríguez, et al., 2017). En el mundo hoy hay numerosos consorcios que exploran el potencial de esta biomasa para transformarla, no solamente en bioenergía y compostaje, sino también en productos de alto valor agregado como los polihidroxialcanoatos (PHA), polímeros biodegradables con diversos usos, como el de los bioplásticos. El desarrollo de nuevas y avanzadas tecnologías de procesamiento de la biomasa de residuos permitirá, en algún momento, que este material no sea enviado a los rellenos sanitarios sino que se utilice como materia prima de procesos circulares de 
elaboración de valiosos e innovadores productos (Bell, et al., 2018). Para los residuos agroindustriales se utilizan diversos sistemas de procesamiento y valorización que permiten la recuperación de compuestos bioactivos y componentes alimenticios (fibras dietéticas, pigmentos oligosacáridos, flavonoides, carotenoides, pectinas), así como la obtención de enzimas, antibióticos, hongos comestibles, ácidos orgánicos y biocombustibles, y el uso del compostaje como fertilizante y para la recuperación de suelos.

En relación con consideraciones de salud humana, aunque el tema no se aborda en el presente documento, es necesario destacar que la industria médica y de cuidado de la salud es uno de los sectores más activos en la bioeconomía mundial y que su aprovechamiento de los avances en la tecnología del ADN recombinante ha tenido un importante papel en el desarrollo de nuevos productos, tratamientos, vacunas, servicios diagnósticos y biofármacos, los cuales incluyen la insulina (a partir de la década de 1980), los anticuerpos monoclonales para diagnóstico o terapias, el interferón, la eritropoyetina, y los moduladores enzimáticos, entre otros (Lokko, et al., 2018).

\section{Transición a una bioeconomía sostenible a nivel global}

Actualmente, más de 40 países promueven activamente la bioeconomía, con el fin de responder a los retos del desarrollo sostenible. Los gobiernos deben reflexionar sobre el amplio potencial de los recursos biológicos y del alcance de sus múltiples aplicaciones. Para que el enfoque bioeconómico se convierta en el motor de la transformación hacia la sostenibilidad en un contexto de economía circular, es indispensable un enfoque más sistemático, intersectorial e internacional. Las políticas bioeconómicas no pueden estar fragmentadas en esferas tecnológicas separadas, sino que las estrategias de investigación, desarrollo e innovación deben articular en forma integrada los sectores de la agricultura forestal y marina, de la salud y los alimentos, de las biotecnologías y las tecnologías convergentes, las energías renovables y la conservación y manejo ambientales, todo ello combinado con la sistematización de la información y la digitalización (Global Bioeconomy Summit - GBS, 2015b).

En consonancia con el Acuerdo de París del 2015, numerosos países buscan responder a la reducción de emisiones y la sostenibilidad mediante la creación de empleos y el crecimiento económico con inversión y tecnologías bajas en carbono. La transición de las fuentes de energía y los materiales no renovables hacia la de recursos renovables va a requerir tiempo, pues son numerosos los obstáculos técnicos, sociales y políticos. En el proceso hay que responder a muy diversos desafíos: además de considerar la seguridad energética, la seguridad alimentaria y nutricional y la del agua, también se debe atender al cambio climático (Philp, 2018). En este contexto, la bioeconomía se ha convertido en parte integral de las estrategias de desarrollo en muchos países del mundo. En general, las estrategias de los países se fundamentan en una agricultura más eficiente para incrementar la producción de alimentos y la de biomasa para la producción de biocombustibles y otros bioproductos. Al adoptar este enfoque, se hace necesario reconciliar la agricultura y las necesidades de la industria frente a la biomasa y la tierra (Jiménez-Sánchez \& Philp, 2015). La tendencia mundial hacia la bioeconomía se despliega en diversas dimensiones dependiendo de las condiciones naturales, sociales y políticas. El desarrollo de bioeconomías inteligentes y sensatas necesita de sólidos conceptos científicos, de soporte a largo plazo en la innovación centrada en la misión, y de un equilibrio sensato entre el impulso de la ciencia y la demanda social y del mercado.

El concepto de bioeconomía se ha venido promoviendo alrededor del mundo desde 1997; entre otros, lo ha impulsado la American Association for the Advancement of Science, y en el 2012 la administración Obama presentó su estrategia oficial llamada "Plan Nacional de Bioeconomía" (National Bioeconomy Blueprint) en las áreas de investigación, desarrollo e innovación de las ciencias biológicas para generar actividad económica y beneficio público en diversos campos como el de los nuevos fármacos, el rendimiento de los cultivos, la producción de biocombustibles novedosos y de productos químicos de base biológica, entre otros (Lewandowski, 2018).

Según la última actualización del informe del Consejo Alemán de Bioeconomía sobre estrategias nacionales de bioeconomía alrededor del mundo (Consejo Alemán de Bioeconomía - BÖR, 2018), la bioeconomía ha cobrado mayor impulso a nivel global. En los inicios del 2018, cerca de 50 países incluían estrategias de bioeconomía en sus planes de desarrollo, y se han establecido estrategias sub-regionales. Es claro que hay una búsqueda afanosa de armonizar la humanidad con la naturaleza y, paralelamente, promover la innovación en industrias que generen oportunidades de desarrollo y de empleo. El punto clave es que la transición hacia una bioeconomía sostenible requiere de la articulación de políticas y de la colaboración científica internacional (Consejo Alemán de Bioeconomía - BÖR, 2018). Todas estas estrategias se encuentran alineadas con los objetivos de desarrollo sostenible en busca del crecimiento económico doméstico, la protección ambiental, la competitividad y el empleo que promuevan la inclusión social.

La bioeconomía está recibiendo cada vez mayor atención a nivel regional. A continuación se presenta el listado de los países que cuentan con políticas definidas o estrategias en bioeconomía, incluidos los últimos tres años (Consejo Alemán de Bioeconomía - BÖR, 2018). Estas estrategias son variadas y su énfasis se centra en la industrialización de biomasa, la bioenergía, las aplicaciones biotecnológicas; la bioindustria; la economía verde, y la economía azul o economía de los océanos.

Estrategias transnacionales: Unión Europea, Países Nórdicos, OECD, y el Foro Global para la Alimentación y la Agricultura (GFFA).

Estados Miembros del G7 (incluidos también por regiones): Canadá, Francia, Alemania, Japón, Reino Unido y Estados Unidos de América. 
Países BRICS: Brasil, Rusia, India, China y Sudáfrica, todos ellos cuentan con estrategias concretas.

Asia y el Pacífico: Australia, China, India, Indonesia, Japón, Malasia, Nueva Zelanda, Corea del Sur, Rusia, Sri Lanka, Tailandia y Filipinas.

Europa: Alemania, Austria, Bélgica, Dinamarca, España, Finlandia, Francia, Irlanda, Italia, Letonia, Lituania, Países Bajos, Noruega, Portugal, Reino Unido, Suecia y Países Nórdicos del Oeste (Islandia, Islas Feroe, Groenlandia).

África: Kenia, Mozambique, Isla Mauricio, Ghana, Malí, Namibia, Nigeria, Senegal, Sudáfrica, Tanzania, Uganda.

América: Canadá, Estados Unidos de América, Argentina, Brasil, Colombia, Costa Rica, Ecuador, México, Paraguay, Uruguay (No explícito con actividades relacionadas, Chile, Ecuador, Perú).

Llama la atención que los documentos de políticas y estrategias anteriores al 2015 utilizaban diferentes términos y definiciones, como economía biobasada, bioindustria, y economía verde, entre otros, en tanto que en los documentos oficiales de los últimos años el término bioeconomía prevalece claramente. La mayoría de estos documentos hacen énfasis en su carácter transformativo, y se enfocan en la producción y el aprovechamiento de los recursos biológicos para generar, preferentemente, bioproductos de alto valor agregado.

Uno de los ejemplos destacados es la bioeconomía europea, que en el 2013 representaba cerca de 17 millones de empleos, con un volumen de negocios de más de 2 trillones de euros ( $€ 2 \times 1018)$, cifras que se resumen en las figuras 1 y 2 . Actualmente, esta genera cerca de 18 millones de empleos en varias industrias bien establecidas, siendo el mayor el de los empleos en el sector agrícola, seguido por la agroindustria y la industria de alimentos, en tanto que económicamente el mayor volumen se concentra en la producción de alimentos, seguida por la agricultura y las industrias forestales y de pulpa y papel (El-Chichakli, et al., 2016; Lewandowski, 2018). Si bien la economía de base biológica en Europa contribuye a reemplazar combustibles fósiles, no se trata solamente de esto. También se busca desarrollar nuevos sectores emergentes, como el de biomateriales y la denominada química verde, y encontrar nuevos usos competitivos para los recursos naturales y liderar la creación de nuevos mercados mediante la adición de conocimiento (Bell, et al., 2018).

La Unión Europea viene realizando grandes inversiones en tecnologías emergentes, como la biología sintética, la ingeniería metabólica o la química fina de bioproductos, con el fin de incorporar estos avances en el desarrollo de la economía de base biológica. Se buscan, por ejemplo, procesos para la utilización del $\mathrm{CO}_{2}$ emitido por las industrias, lo que podría ser un nuevo elemento crítico para la economía circular, así como una tecnología trascendente para la mitigación del cambio climático. Los potenciales avances tecnológicos podrían llevar a reducciones mundiales de $\mathrm{CO}_{2}$ del orden de 500 a 1.000 millones de toneladas por año (Lewandowski, 2018). Un ejemplo de estos desarrollos tecnológicos es el proyecto BISIGODOS (http://www. bisigodos.eu/) de biorresinas y químicos obtenidos de biorrefinerías de algas, cuyo objetivo es la obtención de bioproductos de alto valor agregado (como bioresinas para revestimientos, tipografía, alimentos, cosméticos y adhesivos), aminoácidos y otros compuestos a partir del cultivo de algas alimentadas directamente con el $\mathrm{CO}_{2}$ proveniente de las emisiones industriales (cemento, acerías, plantas térmicas, etc.), y con luz solar y algunos nutrientes. El proceso utiliza la radiación solar, los nutrientes y la biomasa de microalgas marinas y se basa en la tecnología desarrollada por Biofuel Systems (BFS) para la producción de bioaceite (Bell, et al., 2018). En este mismo sentido, organizaciones como la Fraunhofer de Europa desarrollan y transfieren tecnologías a nivel global. En Latinoamérica se desarrollan actividades en Chile y Brasil.

\section{Bioeconomía en Latinoamérica y el Caribe}

En Latinoamérica y el Caribe el concepto de bioeconomía se ha venido consolidando, y se promueve como modelo alternativo para el desarrollo sostenible y el crecimiento verde. La extraordinaria riqueza en biodiversidad de esta región del mundo y su gran capacidad de producción de biomasa, ofrecen un enorme potencial para la producción y transformación de productos y representa una coyuntura estratégica para promover la diversificación productiva agrícola y agroindustrial. Para ello, es necesario potenciar las capacidades regionales y fortalecer la cooperación científica en biotecnología y otras tecnologías habilitantes (nanotecnología, tecnologías informáticas), promover actividades en bioenergías y la adición de valor a la producción primaria, así como diversificar la base de las economías regionales. Paralelamente, es necesario encausar acciones de reducción de las emisiones y de mitigación y adaptación al cambio climático a lo largo de las cadenas de valor (Rodríguez, et al., 2017). Si bien la región es muy heterogénea, en términos generales cuenta con un buen potencial subutilizado de recursos de infraestructura y de personal capacitado de alto nivel.

No todos los países cuentan con políticas o estrategias explícitas en bioeconomía, aunque algunos, como Argentina, Brasil, Colombia y Ecuador, han manifestado su interés en formularlas. Colombia, Paraguay y Uruguay han iniciado actividades en la bioeconomía basada en el conocimiento (bioprospección, tecnologías agrícolas), en tanto que agencias de cooperación internacional como la Comisión Económica para América Latina y el Caribe de las Naciones Unidas (CEPAL), vienen promoviendo la articulación y la cooperación para el desarrollo de la bioeconomía en aspectos de políticas y alianzas entre el sector privado y la investigación (Consejo Alemán de Bioeconomía - BÖR, 2018). En el caso de Centroamérica, se considera que el potencial de la bioeconomía está ligado directamente con la producción agrícola y con la investigación, el desarrollo 


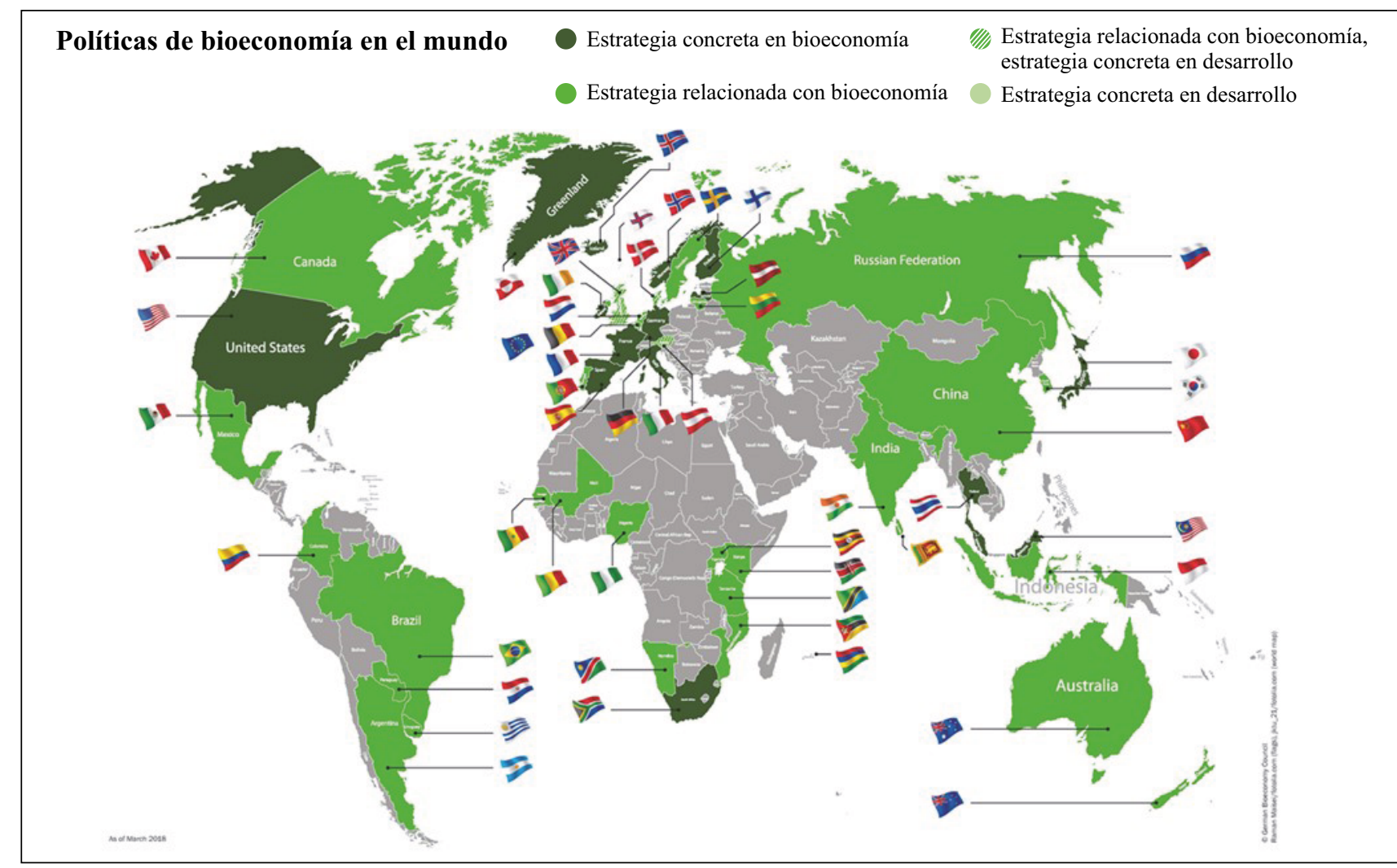

Figura 1. Políticas y estrategias en bioeconomía en el mundo hasta 2017. Fuente: Consejo Alemán de Bioeconomía - BÖR, 2017. (http:// biooekonomierat.de/en/international0/)

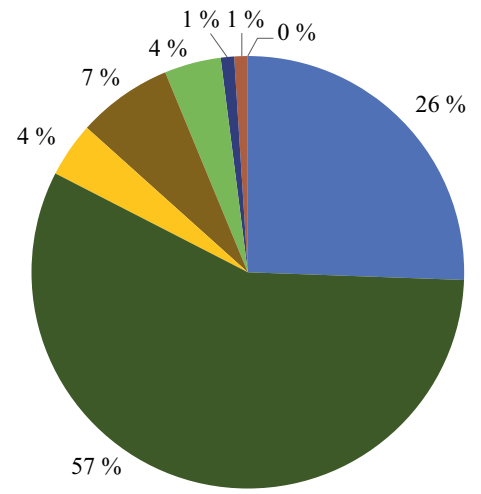

Generación de empleo

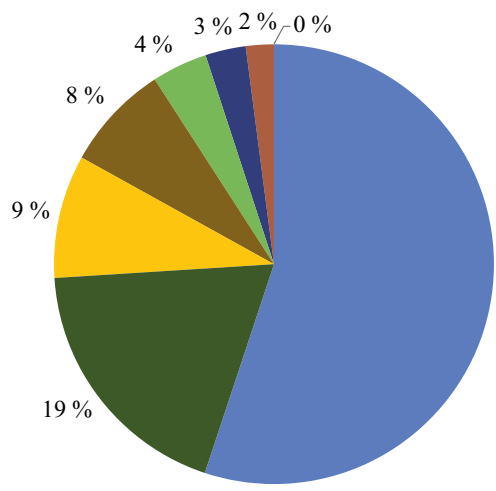

Volumen de negocios
- Alimentos, bebidas y tabaco

- Agricultura

- Industria papelera

- Industria maderera

- Textiles de base biológica

- Químicos de base biológica

- Industria forestal

- Pesquería, Biocombustibles y electricidad bio-basada

\begin{tabular}{|l|c|c|}
\hline Sector & $\begin{array}{c}\text { Empleos (millones) } \\
\text { Total: 17 millones }\end{array}$ & $\begin{array}{c}\text { Volumen de negocios en billones } \boldsymbol{\epsilon} \\
\text { Total: 2 trillones } \boldsymbol{€}(\mathbf{2} \times \mathbf{1 0 1 8})\end{array}$ \\
\hline Alimentos, bebidas y tabaco & 4,3 & 1,12 Trillones $(1,12 \times 1018)$ \\
\hline Agricultura & 9,7 & 380 \\
\hline Industria papelera & 0,6 & 178 \\
\hline Industria maderera & 1,1 & 153 \\
\hline Textiles de base biológica & 0,7 & 78 \\
\hline Químicos de base biológica & 0,2 & 52 \\
\hline Industria forestal & 0,1 & 35 \\
\hline Pesquería, Biocombustibles y electricidad bio-basada & $<0,1$ & $<10$ \\
\hline
\end{tabular}

Figura 2. Bioeconomía en la Unión Europea: generación de empleo y volumen de negocios en el 2013. Fuente: elaboración propia a partir de datos de El-Chichakli, et al., 2016 y Ronzon, et al., 2015 
y la innovación, y algunos grupos han venido trabajando en productos tradicionales nativos subutilizados con potencial de interés. Se considera que es preciso mantener y promover la capacidad de suministro de recursos naturales de estos países, incluidas el agua y la biodiversidad, así como los recursos que permiten ofrecer servicios ecosistémicos, todo ello enmarcado en las actividades de adaptación y mitigación del cambio climático, cuyos efectos se han venido manifestando abiertamente en los últimos años, en especial en el Caribe (Vega \& Madrigal, 2017)

Como base para iniciar la cooperación regional, entre el 2011 y el 2013 se desarrolló un proyecto del Programa 7 de la Comisión Europea "ALCUE-KBBE: hacia una bioeconomía basada en el bioconocimiento en América Latina en asociación con Europa", cuyo objetivo fue establecer una plataforma de cooperación internacional entre la Unión Europea y Latinoamérica y el Caribe en investigación, desarrollo e innovación tecnológica en temas de bioeconomía, en el cual participaron 12 países. El proceso se inició con un análisis comparativo a partir del cual se identificaron cuatro grandes áreas prioritarias para la región: i) bioenergía; ii) procesos y productos biotecnológicos; iii) valorización de la biodiversidad y servicios ecosistémicos, y iv) ecointensificación. Durante los tres años del proyecto se analizaron meticulosamente los recursos naturales renovables de la región, las capacidades en investigación, desarrollo e innovación, la infraestructura disponible, el marco político, normativo e institucional en la región, y se hicieron estudios de caso de experiencias exitosas. En forma complementaria, se analizaron las fortalezas, oportunidades, debilidades y amenazas en un ejercicio transformativo que permitió la detección de acciones estratégicas para la región. Como parte de los resultados del proyecto se publicó el libro "Hacia una bioeconomía en América Latina y el Caribe en asociación con Europa" (Hodson, 2014), entre cuyas conclusiones se destaca que no hay una definición única para la bioeconomía sino que cada región, país o subregión necesita establecer su propia definición y sus delimitaciones con base en las condiciones relevantes, en sus políticas y prioridades y en sus objetivos socioeconómicos, ambientales e institucionales.

Es interesante anotar que tres de los países de la región se ubican entre los primeros cinco que utilizan cultivos genéticamente modificados y son proveedores mundiales de grano (James, 2016). Asimismo, la región genera prácticas agrícolas ecoeficientes, como la agricultura de precisión, la de no labranza, el manejo integrado de plagas y de nutrientes y el uso de enfoques de agricultura orgánica. Por otra parte, la región es líder en la producción de bioenergía (siendo Argentina, Brasil y Colombia los países más avanzados en este campo), y hay esfuerzos ampliamente conocidos para institucionalizar la valorización de la biodiversidad (Rodríguez, et al., 2017). Los esfuerzos de cooperación con la Unión Europea han continuado, principalmente a través del proyecto ALCUE-NET, con el cual se buscó fortalecer la red de cooperación, especialmente con la organización de talleres en áreas temáticas transversales como la biodiversidad, la energía y la bioeconomía. Este programa finalizó en noviembre de 2017 y actualmente se continúa la colaboración a través del Programa Horizonte 2020.

Ha habido avances muy interesantes en algunos de los países de la región. Por ejemplo, en Argentina se ha planteado un proceso nacional para el desarrollo de una estrategia marco de bioeconomía a nivel regional vinculada al concepto de territorios inteligentes (Rodríguez, 2018). El gobierno argentino publicó en el 2017 su documento "Bioeconomía argentina", que presenta el plan de acción para el desarrollo de la bioeconomía en ese país, y, posteriormente, un programa que destaca la necesidad de implementar estrategias en políticas y acciones definidas. Por su parte, la Bolsa de Cereales ha destacado la importancia de los sectores de energía y alimentos, recomendando el desarrollo de políticas en biotecnología para promover su aplicación en la producción de alimentos, en el sector farmacéutico y en la protección ambiental. También el gobierno de Brasil ha promovido desarrollos en bioeconomía por más de cinco décadas con políticas, leyes y estrategias. El enfoque principal ha sido el uso sostenible de la biodiversidad, la biotecnología y la producción de biocombustibles (Consejo Alemán de Bioeconomía - BÖR, 2018). En ese país se destacan dos iniciativas exitosas en el marco de la asociación con la Empresa Brasileira de Pesquisa Agropecuária (Embrapa): Embrapa Agroenergía, cuyo objetivo es desarrollar soluciones tecnológicas con un fuerte componente industrial para que las empresas desarrollen las últimas fases de escalamiento y mercado. Hoy cuentan con 34 tecnologías en estado intermedio de desarrollo (https://www.embrapa.br/agroenergia/vitrine), y Red Passitec de biodiversidad y ciencia para desarrollar tecnologías destinadas al uso funcional de especies silvestres de pasifloras en toda la cadena de suministro y valor. En el 2013 liberaron una variedad de Passiflora setacea, la BRSPC (Pearl Passion Fruit), que en cuatro años se convirtió en el principal ingreso de las familias de la región de Piripau en el Distrito Federal (Torres, 2018):

En cuanto a la bioeconomía en Colombia, desde hace varios años se percibe gran interés en diversas instancias del gobierno para acoger el concepto de desarrollo basado en la bioeconomía, y se han elaborado diversos documentos en biotecnología, gestión de la biodiversidad, innovación e industria. En el Foro Económico Mundial 2016, Colombia lanzó su estrategia de nueva economía basada en la agroindustria, los servicios y el turismo como motores del crecimiento. Además, la dinámica en torno a la conservación de la biodiversidad y el estudio de la vulnerabilidad ante el cambio climático se imponen cada vez más, por lo que se considera que el enfoque de la bioeconomía puede cumplir con un triple propósito al integrar sostenibilidad ambiental, social y económica. En este sentido, está en desarrollo la iniciativa "Misión de Crecimiento Verde" del Departamento 
Nacional de Planeación, la cual finalizará a mediados del 2018 y busca formular la "Política de crecimiento verde" incluyendo la bioeconomía e involucrando de manera estratégica al sector privado. Entre los objetivos de dicha política está asegurar el uso sostenible del capital natural y de los servicios de los ecosistemas, posicionar la bioeconomía como un sector competitivo, y asegurar la inclusión social y el bienestar (Gómez, 2018). Por otra parte, el Programa de Colombia-Bio, liderado por Colciencias, busca "contribuir a un desarrollo sostenible y socialmente inclusivo."

Con el fin de articular e integrar intereses, en abril del 2017 se llevó a cabo el "Foro Nacional de Bioeconomía Innovación territorial sostenible" con la participación, entre otros, de los directores de Corpoica, del Instituto Alexander von Humbodt, Fedepalma, ColombiaBio y el Codirector del Banco de la República. En él se determinaron los siguientes senderos productivos para la bioeconomía en Colombia: el aprovechamiento de los recursos de la biodiversidad, la ecointensificación, la biotecnología para bioproductos, los servicios ecosistémicos, la eficiencia en las cadenas (o redes) de valor, y la eficiencia en biorrefinerías.

En Colombia hay numerosos grupos de investigación y desarrollo con las capacidades necesarias para adelantar actividades que contribuyan a un modelo bioeconómico; el eje central de la mayoría de ellos es la investigación en biotecnología en los sectores agropecuario, de procesamiento de alimentos y de microbiología industrial, fundamentalmente en la producción primaria. Convendría fortalecer sus capacidades para que incorporen en sus trabajos el concepto de la circularidad en las cadenas de valor en su campo y la generación de bioproductos con mayor valor agregado. Un ejemplo interesante son los modelos que han surgido en el sector agropecuario que aplican principios de la bioeconomía a través del desarrollo de bioinsumos que, además de reducir el costo de producción, son claramente más sostenibles. Es innegable que hoy hay en el país numerosas iniciativas a diferentes niveles, desde empresas consolidadas hasta emprendimientos de jóvenes investigadores. Internacionalmente se reconoce la trayectoria en el sector de la bioenergía, y la producción de bioetanol y biodiesel (empresas de caña de azúcar y de aceite), así como las experiencias exitosas en biotecnologías y ecointensificación, incluidos los organismos genéticamente modificados, los bioinsumos, la biorremediación y la industria química. En el campo de la biodiversidad aplicada a la salud hay iniciativas en farmacéutica y fitoquímica, biocosmética y otras aplicaciones. Algunas de estas empresas se destacan por sus desarrollos y avances, como EcoFlora, líder en extractos vegetales para la protección de cultivos, la Fundación Laboratorio de Farmacología Vegetal LABFARVE, con la producción de fitoterapéuticos, y Manuelita S.A., con la de biocombustibles. Recientemente, surgió el proyecto Arthrofood de jóvenes emprendedores colombianos, que es la primera granja de producción de grillos para proteína animal en Latinoamérica.

\section{Aspectos políticos y sociales}

En los últimos años la bioeconomía se ha establecido a nivel mundial como el cimiento de una economía sostenible y amigable con el planeta. La utilización dirigida de recursos biológicos para propósitos industriales contribuye a reconciliar la ecología con la economía y puede promover un cambio fundamental en los procesos industriales (Schütte, 2018). Los descubrimientos disruptivos en biología molecular en los últimos 50 años han llevado a aplicaciones que han cambiado en forma extraordinaria la sociedad. Asimismo, algunas estrategias bioeconómicas han ido desplazando el enfoque técnico y económico relativamente reduccionista hacia uno más amplio y más integrador de la ciencia, la tecnología, la economía, el ambiente, el desarrollo industrial y rural, los procesos regulatorios y las ciencias sociales (Aguilar, et al., 2018).

Un aspecto de gran importancia es la información y la comprensión de la bioeconomía por parte del público, especialmente los aspectos relacionados con los beneficios, los riesgos y las consideraciones éticas, así como la adopción de patrones sostenibles de consumo y producción. Para avanzar en una bioeconomía competitiva y sostenible, es fundamental impulsar la gobernanza participativa para comprometer a toda la sociedad y a todas las partes relevantes en un diálogo abierto e informado, y comprometer a los gobiernos y la industria en los esfuerzos concertados de impulso a la innovación con metas definidas (McCormik \& Kautto, 2013). La aceptación y la adopción de la bioeconomía requieren de una sociedad con "mente biológica" que participe de forma activa y comprometida en los esfuerzos de sostenibilidad y en la protección de los recursos renovables. Para ello es necesario involucrar al público en las discusiones y en la adopción de decisiones en un proceso abierto y ampliamente participativo e inclusivo. El concepto de cascada de valor le confiere a la bioeconomía una naturaleza integradora, con implicaciones para la política pública. Es conveniente evitar la dicotomía entre alimentos y energía. La seguridad alimentaria y la conservación ambiental deben prevalecer por encima de cualquier otra consideración, lo cual va ligado a un razonamiento ético y a las consideraciones sobre el uso recreacional del suelo y los recursos.

El avance adecuado de la bioeconomía exige cumplir con los siguientes cinco supuestos: i) condiciones naturales, que se desprenden de la riqueza de la biodiversidad, los suelos, y condiciones agroclimáticas que potencien la producción de biomasa, bioenergía y bioproductos en forma masiva; ii) recursos laborales y personal capacitado; iii) recursos de conocimiento para fomentar la innovación con las inversiones correspondientes en investigación, desarrollo e innovación; iv) recursos financieros para la inversión en todas las cadenas de valor, especialmente capital de riesgo, y v) infraestructura de apoyo en términos de transporte, información y comunicaciones (Lewandowski, 2018). La adopción exitosa de la bioeconomía requiere un discurso social sobre las formas en que la sociedad puede reconciliar crecimiento económico 
y sostenibilidad, para lo cual se necesita de adaptación y ajuste permanente de iniciativas y agendas, así como de una cooperación internacional eficiente (Schütte, 2018).

En la reciente Cumbre Mundial en Bioeconomía (abril de 2018), se definieron temas de relevancia global para las agendas políticas y de investigación, principalmente enfocados en la relación de la bioeconomía con el cambio climático y el impacto en la salud; la digitalización y las tecnologías convergentes ('bio', 'nano', ‘info'); la comunicación y la confianza del público en las ciencias y tecnologías transformadoras; la educación interdisciplinaria y el entrenamiento a todos los niveles; la biodiversidad como recurso y base de la bioeconomía; la bioeconomía marina y de océanos; las fuentes innovadoras de financiamiento, y la bioeconomía en las ciudades. Entre las recomendaciones se encuentra el establecimiento de mecanismos internacionales de coordinación y de intercambio de conocimientos con los participantes en esta reunión y con organizaciones de las Naciones Unidas a través de foros sobre el desarrollo sostenible, la biodiversidad y la innovación, especialmente el Acuerdo de París sobre el cambio climático (GBS, 2018).

A pesar de sus ventajas evidentes, y como siempre sucede con cualquier cambio de paradigma, se presentan inquietudes y detractores. Hay autores que consideran la bioeconomía como la "neoliberalización" de la naturaleza, es decir, la prevalencia de los valores del mercado, y como una forma de beneficiar el interés de grandes compañías interesadas en comercializar la innovación y las nuevas tecnologías y no a los pequeños productores (Lewandowski, 2018). Algunos de los debates sobre la bioeconomía y los desarrollos biotecnológicos están atravesados por aspectos éticos, ambientales, económicos, sociales y legales, como los derechos de propiedad intelectual y las implicaciones de las patentes en el costo y la accesibilidad de la tecnología en los países en desarrollo, así como la concientización del público y su aceptación de los desarrollos (Krauss \& Kuttenkeuler, 2018).

\section{Conclusiones}

El enfoque de la bioeconomía permite proponer soluciones nuevas a problemas antiguos. Las soluciones de base biológica con frecuencia suministran beneficios innovadores y únicos, lo cual facilita el consumo sostenible (Global Bioeconomy Summit - GBS, 2018). Los avances recientes en ciencia y tecnología han permitido encontrar nuevas funciones y propiedades de los recursos biológicos. Numerosos países vienen adoptando este modelo, y hay una variada gama de bioeconomías alrededor del mundo cuyo desarrollo depende de los recursos naturales disponibles, las capacidades científicas y las tendencias políticas y sociales, aunque todas coinciden en la adopción de modelos de producción y consumo más sostenibles. Es importante destacar que la adopción del modelo de bioeconomía implica una transición y requiere un cambio conceptual en todos los sectores de la sociedad, así como su compromiso decidido para lograr una participación social incluyente.
Una consideración fundamental es cómo incrementar el flujo de los resultados en ciencia y tecnología a su aplicación social para el bien común, de manera que sean un factor de bienestar para la población y, además, un elemento central que contribuya a la sostenibilidad del planeta. Conviene analizar cuáles son los principales problemas relacionados con la sostenibilidad y definir las acciones prioritarias que permitan enfrentarlos, por ejemplo, las biorrefinerías de desechos para valorizar los residuos, una de cuyas posibilidades es la producción de envases y empaques biodegradables a partir de residuos agrícolas.

La transición de una economía fósil a una economía basada en el conocimiento y en el uso juicioso de los recursos biológicos permite enfrentar varios de los retos sociales y las preocupaciones de desarrollo sostenible y constituye una excelente contribución para avanzar en el logro de los objetivos de desarrollo sostenible, especialmente de los siguientes: el objetivo 2, relativo al hambre y la seguridad alimentaria; el 3, a la salud y el bienestar; el 6, al agua limpia y el saneamiento; el 7, a la energía asequible y no contaminante; el 9, a la promoción de la industrialización inclusiva y sostenible; el 11, a las ciudades y comunidades sostenibles; el 12, a la producción y el consumo responsables; el 13, a la acción por el clima; al 14, a la vida submarina, y el 15, a la vida de los ecosistemas terrestres. Con el aporte a estos objetivos, se mejorarían las condiciones del planeta $\mathrm{y}$, por consiguiente, el bienestar y la sostenibilidad de todas las formas de vida.

\section{Conflicto de intereses}

La autora declara que no existe conflicto de intereses en torno al desarrollo de la investigación.

\section{Referencias}

Aguilar, A., Wohlgemuth, R., Twardowski T. (2018) Perspectives on bioeconomy. New Biotechnology. 40: 181-184.

Bell, J., Paula, L., Dodd, T., Németh, S., Nanou, C., Mega, V., Campos, P. (2018). EU ambition to build the world's leading bioeconomy-Uncertain times demand innovative and sustainable solutions. New Biotechnology. 40: 25-30.

Consejo Alemán de Bioeconomía - BÖR. (2017). Bioeconomy policies and strategies established by 2017. Diagram prepared by the German Bioeconomy Council (Bioökonomierat - BÖR), Berlin. Fecha de consulta: marzo de 2018. Disponible en: http://biooekonomierat.de/en/international0/

Consejo Alemán de Bioeconomía - BÖR. (2018). Bioeconomy Policy (Part III) Update Report of National Strategies around the World. A report from the German Bioeconomy Council. Fecha de consulta: abril de 2018. Disponible en: http:/gbs2018.com/fileadmin/gbs2018/Downloads/ GBS_2018_Bioeconomy-Strategies-around-the_World_ Part-III.pdf

Cristóbal, J., Matos, C.T., Aurambout, J.P., Manfredi, S., Kavalov, B. (2016). Environmental sustainability assessment of bioeconomy value chains. Biomass and Bioenergy. 89: 159-171.

El-Chichakli, B., von Braun, J., Lang, C., Barben, D. (2016). Five cornerstones of a global bioeconomy. Nature. 535: 221-223 
European Bioplastics (s.f.). (2018). Facts and figures. Fecha de consulta: marzo de 2018. Disponible en: http://docs. european-bioplastics.org/publications/EUBP_Facts_and figures.pdf

Global Bioeconomy Summit - GBS. 2015. (2015a). Communiqué Global Bioeconomy Summit 2015. Making bioeconomy work for sustainable development. Berlin. Fecha de consulta: enero de 2018. Disponible en: http://gbs2015.com/ fileadmin/gbs2015/Downloads/Communique_final_neu.pdf

Global Bioeconomy Summit - GBS. 2015. (2015b). Conference Report. For a Global Sustainable Bioeconomy. Berlin. Fecha de consulta: noviembre de 2017. Disponible en: http://gbs2015.com/documentation/

Global Bioeconomy Summit - GBS. 2018. (2018a). Communiqué. Global Bioeconomy Summit 2018 - Innovation in the Global Bioeconomy for Sustainable and Inclusive Transformation and Wellbeing. Fecha de consulta: abril de 2018. Disponible en: http://gbs2018.com/fileadmin/ gbs2018/Downloads/GBS_2018_Communique.pdf

Gómez, H.J. (2018). Avances en la formulación de la política pública para el desarrollo de la bioeconomía en Colombia. Departamento Nacional de Planeación. Seminario Regional CEPAL. Fecha de consulta: febrero de 2018. Disponible en: http://conferencias.cepal.org/bioeconomia_AL/

Hodson de Jaramillo, E. (Editor). (2014). Towards a Knowledge Based Bio-Economy in Latin America and the Caribbean. Editorial Javeriana, Bogotá, Colombia.

Hodson de Jaramillo, E., Castaño, J., Poveda, G., Roldán, G., Chavarriaga, P. (2017). Seguridad alimentaria y nutricional en Colombia. En: Retos y oportunidades de la seguridad alimentaria y nutricional en las Américas - El punto de vista de las Academias de Ciencias. Red Interamericana de Academias de Ciencias (IANAS); Red Mundial de Academias de Ciencias (IAP); Ministerio Federal de Educación e Investigación Alemania (BMBF); Academia Nacional de Ciencias de Alemania-Leopoldina. p. 220-249.

James, C. (2016). Global Status of Commercialized Biotech/ GM Crops: 2016. ISAAA Brief No. 52. ISAAA: Ithaca, NY. Fecha de consulta: octubre de 2017. Disponible en: http://www.isaaa.org/resources/publications/briefs/52/ executivesummary/pdf/B52-ExecSum-English.pdf

Jiménez-Sánchez, G. \& Philp, J. (2015). Omics and the bioeconomy. EMBO Reports. 16: 17-20.

Krauss, J.B. \& Kuttenkeuler, D. (2018). Intellectual property rights derived from academic research and their role in the modern bioeconomy-A guide for scientists. New Biotechnology. 40: 133-139.

Lewandowski, I. (Editor). (2018). Bioeconomy - Shaping the Transition to a Sustainable, Biobased Economy. Springer International Publishing. 164 p. Doi: https://doi.org/10. 1007/978-3-319-68152-8

Lokko, Y., Heijde, M., Schebesta, K., Scholtès, P., Van Montagu, M., Giacca, M. (2018). Biotechnology and the bioeconomy - Towards inclusive and sustainable industrial development. New Biotechnology. 40: 5-10
Małyska, A. \& Jacobi, J. (2018). Plant breeding as the cornerstone of a sustainable bioeconomy. New Biotechnology. 40: $129-132$.

McCormik, K. \& Kautto, N. (2013). The Bioeconomy in Europe: An Overview Sustainability. 5 (6): 2589-2608.

Organisation for Economic Co-operation and Development - OECD. (2004). Biotechnology for Sustainable Growth and Development. OECD Publications, Paris. Fecha de consulta: noviembre de 2017. Disponible en: http://www. oecd.org/sti/biotech/23536372.pdf

Patermann, C. \& Aguilar, A. (2018). The origins of the bioeconomy in the European Union. New Biotechnology. 40: 20-24

Philp, J. (2018). The bioeconomy, the challenge of the century for policy makers. New Biotechnology. 40: 11-19

Rodríguez, A.G. (2018). Bioeconomía en América Latina y el Caribe. Seminario Regional CEPAL. Fecha de consulta: febrero de 2018. Disponible en: http://conferencias.cepal. org/bioeconomia_AL/

Rodríguez, A.G., Mondaini, A.O., Hitschfeld, M.A. (2017). Bioeconomía en América Latina y el Caribe. Contexto global y regional y perspectivas. Unidad de Desarrollo Agrícola, División de Desarrollo Productivo y Empresarial de la Comisión Económica para América Latina y el Caribe. Serie Desarrollo Productivo CEPAL (215). 94 p.

Ronzon, T., Santini, F., M'Barek, R. (2015). The Bioeconomy in the European Union in numbers. Facts and figures on biomass, turnover and employment. European Commission, Joint Research Centre, Institute for Prospective Technological Studies, Spain, $4 p$. Fecha de consulta: febrero de 2018. Disponible en: https://ec.europa.eu/jrc/sites/jrcsh/ files/JRC97789\%20Factsheet_Bioeconomy_final.pdf

Sarkar, S.F., Poon, J.S., Lepage, E., Bilecki, L., Girard, B. (2018). Enabling a sustainable and prosperous future through science and innovation in the bioeconomy at agriculture and agri-food Canada. New Biotechnology. 40: 70-75.

Schütte, G. (2018). What kind of innovation policy does the bioeconomy need? New Biotechnology. 40: 82-86.

Torres, D.A. (2018). Construyendo Bioeconomía en Brasil Embrapa. En: Iniciativas exitosas de bioeconomía en América Latina: investigación y desarrollo. Bioeconomía en América Latina y el Caribe. Seminario Regional. CEPAL. Fecha de consulta: febrero de 2018. Disponible en: http://conferencias.cepal.org/bioeconomia_AL/

Vega M.M. \& Madrigal O.Q. (2017) International Bioeconomy Innovations in Central America. In: Dabbert S., Lewandowski I., Weiss J., Pyka A. (editors). KnowledgeDriven Developments in the Bioeconomy. Economic Complexity and Evolution. Springer, Cham. p. 83-96. 